\title{
Optimization of Combustion Characteristics of Blended Coals Based on TOPSIS Method
}

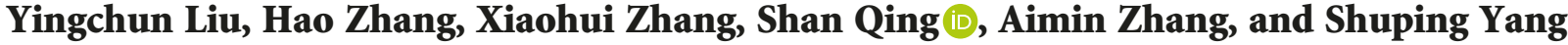 \\ State Key Laboratory of Complex Nonferrous Metal Resources Clean Utilization, Department of Metallurgical and \\ Energy Engineering, Kunming University of Science and Technology, Kunming, Yunnan 650093, China \\ Correspondence should be addressed to Shan Qing; 15087088903@163.com
}

Received 20 June 2018; Accepted 27 August 2018; Published 2 December 2018

Academic Editor: Zhile Yang

Copyright ( 2018 Yingchun Liu et al. This is an open access article distributed under the Creative Commons Attribution License, which permits unrestricted use, distribution, and reproduction in any medium, provided the original work is properly cited.

\begin{abstract}
The Technique for Order Preference by Similarity to an Ideal Solution (TOPSIS) method is used to find optimal mixing scheme of Zhaotong lignite, Fuyuan bituminous coal, and Xiaolongtan lignite in terms of combustion performance. Comparative evaluation of different mixing schemes is also conducted, where the flammability index, comprehensive combustion characteristic index, burnout temperature, and economic costs can be used to measure the advantages and disadvantages of different mixing schemes with different parameters. Through analysis and optimization, it is found that when the lignite of Xiaolongtan, lignite of Zhaotong, and bituminous coal of Fuyuan are mixed with a ratio $2: 1: 2$, the mixed coal has the best performance; when the lignite of Xiaolongtan, lignite of Zhaotong, and bituminous coal of Fuyuan are mixed with a ratio $0: 2: 1$, the mixed coal has the worst performance.
\end{abstract}

\section{Introduction}

With the development of the electric power industry, more and more power plants have begun to use mixed coal combustion technology, so that the application of mixed coal combustion has brought more and more problems. However, it is also well-known that the mix scheme for the coals is crucial for the combustion performance. Hence, many scholars have gradually paid attention to the research of mixed coal $[1,2]$ to find appropriate optimal mix scheme to seek for better combustion performance. In particular, they mainly improve mixed coal combustion technology by mixing methods, combustion characteristics, burn-up, slagging rate, and emission reduction of pollutants in blended coal $[3,4]$.

Coal blending can be achieved by adopting and optimizing coal blending methods to improve the combustion technology of blended coal, increase the utilization of coal at all levels, and reduce the slagging rate, the pollutant emissions, and the costs [5]. The research on optimization of coal blending technology can potentially solve the energy shortage problem from the supply and demand and ensure the stability and reliability of production from the quality [6-8]. At the same time, the optimization of coal blending technology can provide additional benefits such as environmental protection and effective use of resources [9]. There are differences in the quality of various coals, and the dynamic coal blending mainly uses this basic principle to remove inferior coal from different coal quality $[10,11]$. The excellent characteristics of the blended coal species can be used to make the blended coal show the best performance in comprehensive performance to better meet the needs of end users [12].

Based on some latest research results, it has been found that the characteristics of many blended coals are not with a simple linear superposition relationship. Specifically, the greater the difference in coal quality, the more significant this situation is [13]. Peralta et al. [14] studied the interactions among the blended coals and found that the quality of the coals determines the combustion condition of the blended coal. The combustion depends on the ratio of easily ignited coal. The burnout characteristics of the blended coal depend also on slow burning coal $[15,16]$.

There are mainly three viewpoints for power coal blending [17]. The first is that there is a linear weighted relationship between the dynamic coal blending and the main 
indexes of each component coal, and thus, a linear programming model may be established. The second view states that there is a complex nonlinear relationship between the coal blending and the main indexes of each coal composition, and thus, neural network techniques and fuzzy logic systems can be used to establish nonlinear optimization models. The third point of view is that the linear and nonlinear relationship between the coal blending and the main indexes of each individual coal is not yet fully clear. In this case, the optimization of power blending is not yet clear, and thus, it is still a challenge to develop an accurate, stable, and efficient optimization algorithm.

Multiple Criteria Decision Analysis (MCDA) can be used to analyze various problems in the system planning, designing, and the subsequently encountered production phases [18]. Moreover, this method also has the ability to predict and analyze some problems to appear in the future effectively. In general, this method can also solve the problems with optimization such as formula ratio, which can be widely encountered in the energy, environment, population, and other areas and fields.

To solve complex optimization problem, the Technique for Order Preference by Similarity to an Ideal Solution (TOPSIS) method has been used to study the relationship of the ratio for the mixed coal among three kinds of coals (Zhaotong lignite, Fuyuan coal, and Xiaolongtan lignite mixed ratio). TOPSIS has been proved as an effective approach in many multiobjective decision analysis applications [19]. TOPSIS method has a more detailed name-the method of distance between good and bad results. It is different from the direct method of solving the solution of noninferior problems. When directly solving the noninferior solution, a series of noninferior solutions will be obtained at the same time. Then, it will be judged by the previously determined evaluation criteria, and the most suitable solution will be found therein. The TOPSIS method will use the existing solution to approximate the previous ideal solution and sort them according to this standard [20]. Therefore, we only need to consider the monotonic or monotonic decreasing properties of the utility functions by using this solution method. In other words, this method first examines the distance between the object under test and the best or worst solution. Then, we can sort them and choose the best solution. The solution with the longest distance from the worst solution is the best solution for the constituency. The opposite is considered as the worst solution.

Motivated by the above discussions, this paper will further tailor the TOPSIS method to study the optimization problem of the coal blending, which aims to find the optimal mix scheme for different coals with the best combustion performance. We choose the flammability index, comprehensive combustion characteristic index, burnout temperature, and economic costs to measure the advantages and disadvantages of different mixing schemes with different parameters. Then, the optimal technique is conducted to find the best ratio of different coals. Extensive experiments are carried out to validate the proposed optimization technique. We divide the experiment into 10 groups. Each group has three kinds of coal (lignite of Xiaolongtan, lignite of Zhaotong, and bituminous coal of Fuyuan) with different proportions. The TOPSIS method is used to analyze the combustibility, economy, flammability, and comprehensive combustion characteristics of the combustion of coal under different ratios. The advantages and disadvantages of using TOPSIS method to evaluate coal blending different proportional reference assignment scheme are discussed. Analysis and experimental results show that the Xiaolongtan lignite: Zhaotong lignite:bituminous coal of Fuyuan $=2: 1: 2$ mixed coal is the best mix ratio with the best performance.

This paper is structured as follows: Section 2 gives the formulation of the problem. Section 3 describes the procedure of decision analysis of TOPSIS method. Section 4 gives the research on Blended Coal Combustion. Section 5 gives the method of TOPSIS for evaluation of mixed coal combustion. Conclusions are given in Section 6.

\section{Problem Formulation}

Mixed coal combustion requires full consideration of its ignition characteristics, volatile precipitation characteristics, slagging, burn-up, and pollutant emissions [21]. However, the blending ratio of coal blending in most of the actual process is blind and arbitrary so that the combustion performance of this coal blending cannot be guaranteed. This article aims to discuss the pros and cons of different proportions of mixed coal by TOPSIS method, including its flammability index, comprehensive combustion characteristics index, burnout temperature, and economic cost, and finally get the best ratio of three kinds of coal blended coal combustion.

Under different $\mathrm{O}_{2} / \mathrm{CO}_{2}$ atmospheres, thermogravimetric experiments were performed on mixed coals of three experimental coal samples [22, 23]. The TOPSIS method was used to analyze and optimize the pros and cons of different proportioning schemes to find the optimal ratio. Figure 1 provides the overall research methodology to be presented in this paper.

First of all, the three kinds of coals are divided into several groups according to different proportions; different groups include one kind of coal and a mixture of three kinds of coal, respectively. In the air atmosphere, 30\% oxygen atmosphere, $50 \%$ oxygen atmosphere and the heating rate of $5 \mathrm{~K} / \mathrm{min}, 10 \mathrm{~K} / \mathrm{min}$, and $20 \mathrm{~K} / \mathrm{min}$, respectively, TOPSIS method is used to study the properties and optimal ratio of blending coal.

\section{Blended Coal Combustion Studies}

This paper mainly studies the characteristics of combustion of mixed Xiaolongtan lignite, Fuyuan bituminous coal, and Zhaotong lignite coal blended in Yunnan Province, China. Through the study of the combustion characteristics of the three kinds of coals with different mixing ratios, the TOPSIS method was used to optimize the mix scheme, and finally, the best mix ratio was determined.

Three kinds of different coal powders were selected as experimental objects: Xiaolongtan lignite, Fuyuan bituminous coal, and Zhaotong lignite. The results of industrial 


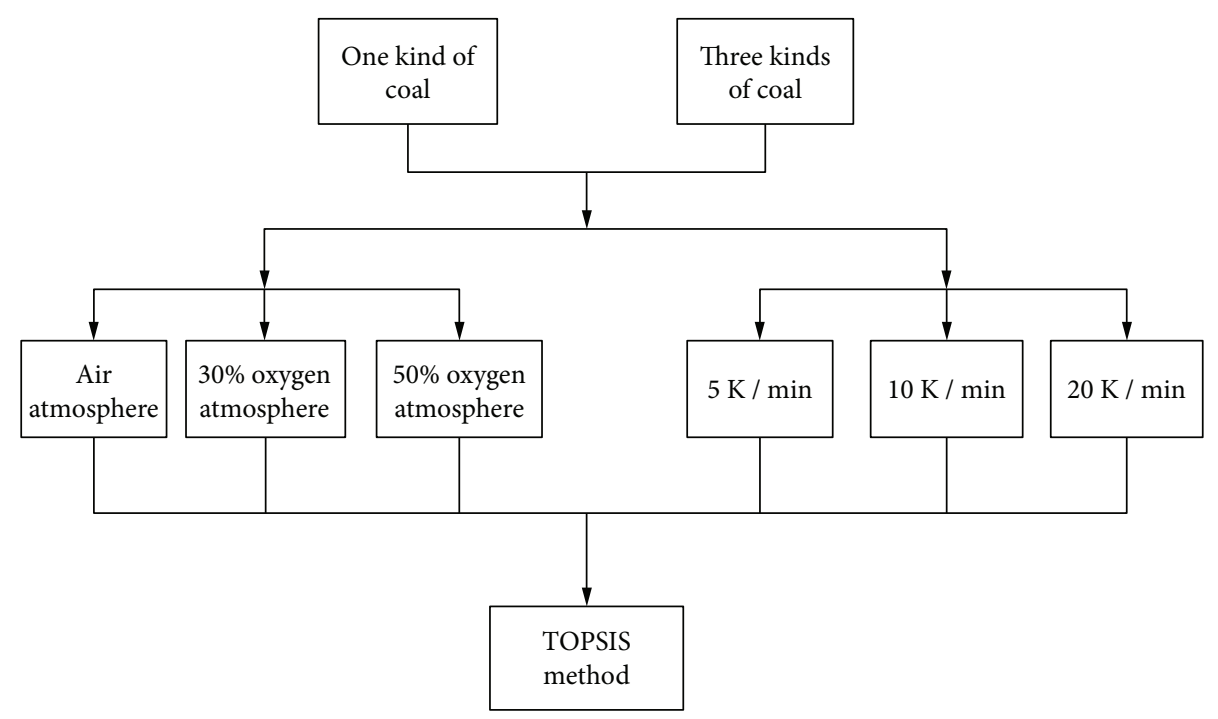

FIgURE 1: Research method.

TABLE 1: Industrial analysis of coal samples.

\begin{tabular}{lcccc}
\hline \multirow{2}{*}{ Type of coal } & \multicolumn{4}{c}{ Industrial analysis } \\
& $\mathrm{M}_{\mathrm{ad}}$ & $\mathrm{A}_{\mathrm{ad}}$ & $\mathrm{V}_{\mathrm{ad}}$ & $\mathrm{FC}_{\mathrm{ad}}$ \\
\hline Xiaolongtan lignite & 15.684 & 10.534 & 40.677 & 33.105 \\
Fuyuan bituminous coal & 2.861 & 37.601 & 14.740 & 44.798 \\
Zhaotong lignite & 6.293 & 29.642 & 42.253 & 21.812 \\
\hline
\end{tabular}

analysis and elemental analysis of different pulverized coals are shown in Tables 1 and 2. The coal sample was ground by a ball mill, and the pulverized coal with a particle size of 53-75 $\mu \mathrm{m}$ was selected. The atmosphere in the furnace uses air and an $\mathrm{O}_{2} / \mathrm{CO}_{2}$ gas mixture of $30 \%$ oxygen and a highpurity argon gas (purity of 99.9\%).

In this paper, we carry out extensive experiments to validate the different mix schemes. The schematic of the adopted experimental equipment is shown in Figure 2.

Three kinds of coal samples including Xiaolongtan lignite, Fuyuan bituminous coal, and Zhaotong lignite were selected as the research objects. Under the oxygen concentrations of $21 \%$ and $30 \%$, the heating rates were set to $5 \mathrm{~K} / \mathrm{min}$, $10 \mathrm{~K} / \mathrm{min}$, and $20 \mathrm{~K} / \mathrm{min}$, respectively.

The specific operation steps of the experiments are described as follows:

(1) The coal sample carrier gas is $\mathrm{O}_{2} / \mathrm{CO}_{2}$, and the protection gas is high-purity argon. The gas from the cylinder is regulated by the pressure-reducing valve and enters the thermobalance. We turn on the instrument and wait for the thermal analyzer to show a stable number. After opening the oven cavity, we put in the previously prepared open crucibles and wait for the reading to become stable, then we clear the reading, complete the baseline, and take out the empty crucibles. After taking about 10 milligrams of coal sample with a small spoon, we can place it in the sample crucible. Using a pair of tweezers, we place the file gently into the oven chamber of the thermogravimetric analyzer. Then, we can close the oven chamber and start the experiment

(2) During the experiment, the carrier gas flow rate was $50 \mathrm{~mL} / \mathrm{min}$, the shielding gas flow rate was $20 \mathrm{~mL} / \mathrm{min}$, and the program temperature-rising method was used to control the temperature that increases from room temperature to $1000^{\circ} \mathrm{C}$. The heating rate was controlled to be $5 \mathrm{~K} / \mathrm{min}, 10 \mathrm{~K} / \mathrm{min}$, and $20 \mathrm{~K} / \mathrm{min}$, respectively. The main experimental subjects used a heating rate of $20 \mathrm{~K} / \mathrm{min}$

(3) Finally, the data is collected and the experiment is completed

Table 3 shows experimental data for the four indexes of combustible coal flammability index, comprehensive combustion characteristics index, burnout temperature, and economic cost of each group. By comparing and calculating with these data, the combustion results of the blended coal can be obtained. Then, the optimal solution can be found by the TOPSIS method.

\section{Procedure of Decision Analysis of TOPSIS Method}

We first normalize the evaluation index. During the experiments, we assume that the kinds of ratio of programs is $m$, the number of indicators to evaluate the number is $n . u_{i j}$ can also be determined as the $i$-th program in the $j$-th index. Then, the corresponding data for the initial evaluation matrix $\mathbf{U}$ is

$$
U=\left[\begin{array}{ccc}
u_{11} & \cdots & u_{1 n} \\
\vdots & \ddots & \vdots \\
u_{m 1} & \cdots & u_{m n}
\end{array}\right]
$$


TABLE 2: Elemental analysis of coal samples.

\begin{tabular}{lcccccc}
\hline \multirow{2}{*}{ Type of coal } & & \multicolumn{3}{c}{ Elemental analysis } & $\mathrm{O}_{\mathrm{ad}}$ & $\mathrm{N}_{\mathrm{ad}}$ \\
\hline Xiaolongtan lignite & $\mathrm{M}_{\mathrm{ad}}$ & $\mathrm{A}_{\mathrm{ad}}$ & $\mathrm{C}_{\mathrm{ad}}$ & $\mathrm{S}_{\mathrm{ad}}$ \\
Fuyuan bituminous coal & 15.684 & 10.534 & 47.264 & 6.991 & 16.683 & 1.741 \\
Zhaotong lignite & 2.861 & 37.601 & 45.82 & 9.243 & 1.231 & 1.615 \\
\hline
\end{tabular}

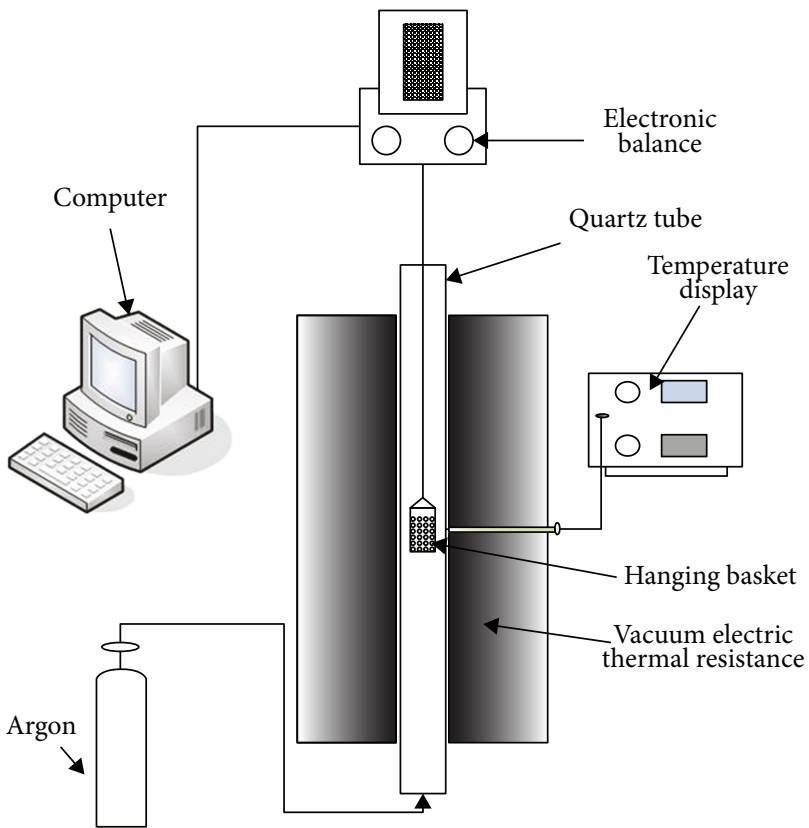

FIGURE 2: Blending coal combustion characteristics experimental equipment schematic.

In order to analyze and compare data in a better way and avoid the influence of different dimensions on matrix $\mathbf{U}$, we need to normalize the representation of the initial data (the specific dimension of each evaluation index is different) as

$$
V_{i j}=\frac{u_{i j}}{\sum_{i=1}^{m} u_{i j}} .
$$

The new nominalized evaluation criterion matrix is obtained by the following calculation:

$$
V=\left\{V_{i j}\right\}_{m \times n} .
$$

Then, we need to calculate the weights of each index. In mathematics, entropy is a measure of the uncertainty of evaluation information which has been used in probability theory. The value of entropy would be large if the data distribution is more dispersed or the uncertainty of itself is greater. In the TOPSIS method, the weight formula of the item $j$ index can be expressed as

$$
Q_{j}=\frac{p_{j}}{\sum_{i=1}^{m} p_{j}},
$$

where $p_{j}$ is the degree of dispersion of the value of the first $j$ index. It is also the information entropy and the difference between 1 , which can be expressed as

$$
p_{j}=1-e_{j} \quad j=1,2, \ldots, n,
$$

where $e_{j}$ is the evaluation of information entropy index, and its expression is given by

$$
e_{j}=-k \sum_{i=1}^{m} v_{i j} \ln v_{i j}
$$

The constants associated with $m$ are expressed in $k, k=1 /(\ln m)$.

If we evaluate the matching scheme by using TOPSIS method on the new standard matrix $\mathbf{V}$ and weight factor $Q_{j}$, we can get the weighting evaluation matrix $R$ of the matching scheme:

$$
R=\left[\begin{array}{ccc}
q_{1} y_{11} & \cdots & q_{n} y_{1 n} \\
\vdots & \ddots & \vdots \\
q_{1} y_{m 1} & \cdots & q_{n} y_{m n}
\end{array}\right]=\left[\begin{array}{ccc}
r_{11} & \cdots & r_{1 n} \\
\vdots & \ddots & \vdots \\
r_{m 1} & \cdots & r_{m n}
\end{array}\right],
$$

where $Q=\left(q_{1}, q_{2}, \ldots, q_{n}\right)^{\mathrm{T}}$ is the weight factor matrix.

$$
V=\left[\begin{array}{ccc}
y_{11} & \cdots & y_{1 n} \\
\vdots & \ddots & \vdots \\
y_{m 1} & \cdots & y_{m n}
\end{array}\right]
$$

is the new standard matrix.

Determine the most ideal and worst index weighted value as $R^{+}$and $R^{-}$, respectively. The negative ideal value as mentioned is the minimum index in the collection. And the set of the maximum value is represented by the weighted ideal index.

$$
R^{+}=\left\{\left(\max r_{i j} \mid j \in J_{1}\right),\left(\min r_{i j} \mid j \in J_{2}\right), i=1,2, \ldots, m\right\},
$$

$$
R^{+}=\left\{\left(\min r_{i j} \mid j \in J_{1}\right),\left(\max r_{i j} \mid j \in J_{2}\right), i=1,2, \ldots, m\right\} .
$$


Table 3: Performance index of mixed coals with different proportions.

\begin{tabular}{|c|c|c|c|c|c|}
\hline Program & $\begin{array}{c}\text { Xiaolongtan: } \\
\text { Zhaotong: Fuyuan }\end{array}$ & $\begin{array}{l}\text { Flammability index } \\
\qquad \mathrm{C} \times 10^{-7}\end{array}$ & $\begin{array}{l}\text { Comprehensive combustion } \\
\text { characteristic index } S \times 10^{-10}\end{array}$ & $\begin{array}{c}\text { Burnout } \\
\text { temperature } \\
T_{h} /{ }^{\circ} \mathrm{C}\end{array}$ & $\begin{array}{l}\text { Economic cost } \\
\text { S/yuan per ton }\end{array}$ \\
\hline 1 & $1: 1: 1$ & 35.95 & 3.37127 & 700 & 383 \\
\hline 2 & $0: 1: 2$ & 30.90 & 2.39214 & 706 & 490 \\
\hline 3 & $0: 2: 1$ & 28.15 & 2.08380 & 718 & 380 \\
\hline 4 & $1: 0: 2$ & 32.77 & 3.72810 & 711 & 493 \\
\hline 5 & $1: 2: 0$ & 38.25 & 3.23677 & 683 & 273 \\
\hline 6 & $1: 2: 2$ & 28.80 & 2.50959 & 698 & 404 \\
\hline 7 & $2: 0: 1$ & 30.88 & 3.06333 & 680 & 387 \\
\hline 8 & $2: 1: 0$ & 43.77 & 4.59559 & 689 & 277 \\
\hline 9 & $2: 1: 2$ & 51.48 & 5.57101 & 690 & 406 \\
\hline 10 & $2: 2: 1$ & 32.39 & 2.79062 & 720 & 340 \\
\hline
\end{tabular}

In the formula, the efficiency index collection is determined by $J_{1}$, and the cost index is determined by $J_{2}$.

Then, we can calculate the distance between them. The content of this part is the calculation of the distance between the practical solution and the ideal solution (the ideal solutions include positive ideal and negative ideal). You can use the Euclidean formula, which can be given as follows:

The distance between the positive ideal solutions is

$$
L_{1}^{+}=\sqrt{\sum_{j=1}^{n}\left(r_{i j}-r_{j}^{+}\right)^{2}}, \quad i=1,2, \ldots, m .
$$

The distance between the negative ideal solutions is

$$
L_{1}^{-}=\sqrt{\sum_{j=1}^{n}\left(r_{i j}-r_{j}^{-}\right)^{2}}, \quad i=1,2, \ldots, m .
$$

Then, we determine the relative proximity. The index value of the best and the most ideal index set and the selected ratio of the selected formula are determined by the above formula. Similarity (proximity) between the two is given by

$$
S_{i}=\frac{L_{i}^{-}}{\left(L_{i}^{+}+L_{i}^{-}\right)}
$$

Finally, in order to arrange the data of the similar degree, we reorder them from large to small in this paper. And then, we can choose the best matching scheme from all the data of the similar degree.

In conclusion, the flow chart of TOPSIS method is shown in Figure 3.

Currently, there are many multiobjective comprehensive evaluation methods of sorting the problem [24-26]. Among these, the TOPSIS method is simple and easy to calculate

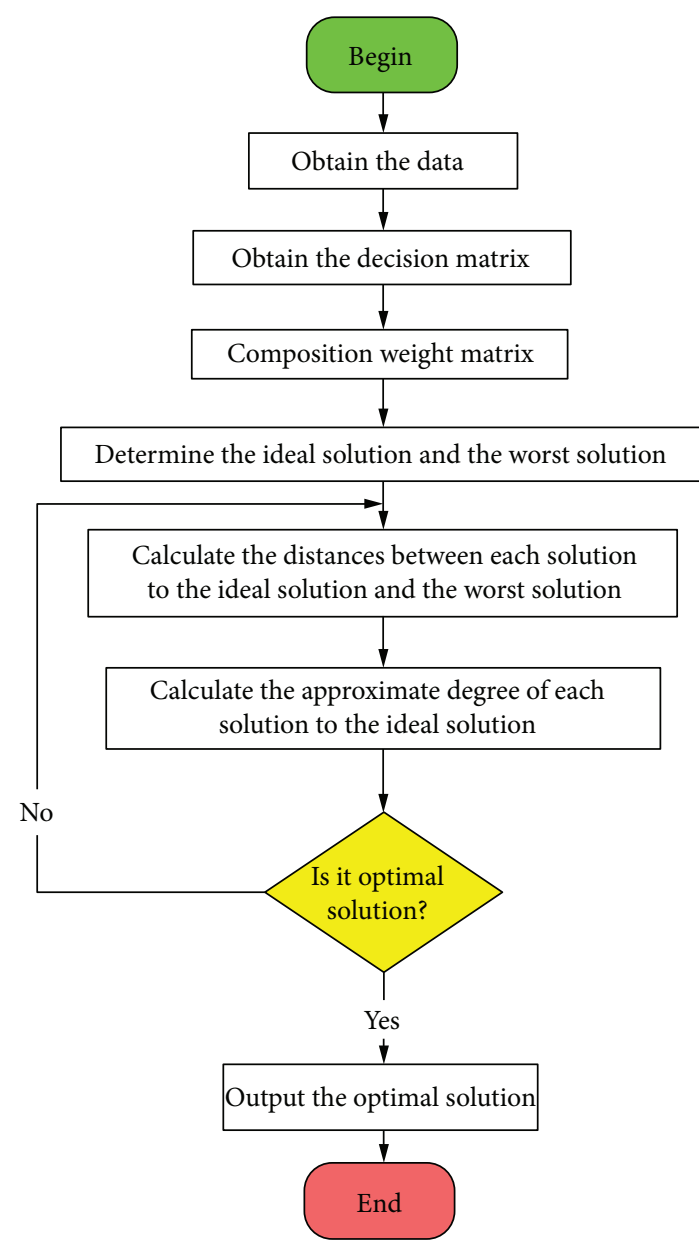

FIGURE 3: The flow chart of TOPSIS method.

the data, and the information of the original data can be fully utilized [27]. Moreover, the calculation results can be very accurate to reflect the gap between different matching 
schemes. The TOPSIS method is suitable for small sample data, multiple evaluation objects, and multiple index large sample data. Hence, in this paper, we use TOPSIS method to comprehensively evaluate the scheme of the mixed coal to get better evaluation results.

\section{TOPSIS for Evaluation of Mixed Coal Combustion}

Three kinds of pulverized coals (bituminous coal of Fuyuan, lignite of Xiaolongtan, and lignite of Zhaotong) are mixed with different proportions. Selection of the four indexes contains flammability index, comprehensive combustion characteristic index, temperature of burnout, and economic costs, which have been used as the performance evaluation index of coal. Table 3 is the four index of the flammability index, comprehensive combustion characteristic index, burnout temperature, and economic costs of the mixed coals based on the experiment and the corresponding data analysis.

\subsection{Matrix of Initial Data of Mixed Coal with Different Ratio.}

$$
U=\left[\begin{array}{ccc}
u_{11} & \cdots & u_{1 n} \\
\vdots & \ddots & \vdots \\
u_{m 1} & \cdots & u_{m n}
\end{array}\right]
$$

$$
=\left[\begin{array}{llll}
35.95 & 3.37127 & 700 & 383 \\
30.90 & 2.39214 & 706 & 490 \\
28.15 & 2.08380 & 718 & 380 \\
32.77 & 3.72810 & 711 & 493 \\
38.25 & 3.23677 & 683 & 273 \\
28.80 & 2.50959 & 698 & 404 \\
30.88 & 3.06333 & 680 & 387 \\
43.77 & 4.59559 & 689 & 277 \\
51.48 & 5.57101 & 690 & 406 \\
32.39 & 2.79062 & 720 & 340
\end{array}\right] .
$$

In the formula, the number of matching scheme is $m$, the number of performance indicators is $n$, i.e., $m=10, n=4$, and $X_{i j}$ represents the element values in the matrix. For example, the $i$ blending scheme in the $j$ index is defined as $X_{i j}$. Then, the normalization process is completed for each evaluation index.

An example of flammability index is given by using the following formula:

$$
V_{i j}=\frac{u_{i j}}{\sum_{i=1}^{m} u_{i j}} .
$$

We can obtain

$$
V_{11}=\frac{35.95}{(35.95+30.90+28.15+32.77+38.25+28.80+30.88+43.77+51.48+32.39)}=0.101752399
$$

Similarly, we can seek out other data in turn and obtain their corresponding values as

$$
\begin{aligned}
V_{11} & =0.101752399, \\
V_{12} & =0.087435362, \\
V_{13} & =0.079675474, \\
V_{14} & =0.092742019, \\
V_{15} & =0.108256791, \\
V_{16} & =0.081510122, \\
V_{17} & =0.087392729, \\
V_{18} & =0.123882589, \\
V_{19} & =0.145697422, \\
V_{110} & =0.091655093,
\end{aligned}
$$

In the same way, the 3 evaluation indexes are also normalized, and we eventually get the following standard matrix as

$$
V=\left\{v_{i j}\right\}_{m \times n}=\left[\begin{array}{llll}
0.1018 & 0.1011 & 0.1001 & 0.0999 \\
0.0874 & 0.0717 & 0.1009 & 0.1278 \\
0.0797 & 0.0625 & 0.1026 & 0.0991 \\
0.0927 & 0.1118 & 0.1016 & 0.1286 \\
0.1083 & 0.0971 & 0.0976 & 0.0712 \\
0.0815 & 0.0753 & 0.0998 & 0.1054 \\
0.0874 & 0.0919 & 0.0972 & 0.1010 \\
0.1239 & 0.1378 & 0.0985 & 0.0723 \\
0.1457 & 0.1671 & 0.0986 & 0.1059 \\
0.0917 & 0.0837 & 0.1029 & 0.0887
\end{array}\right] .
$$

5.2. Calculate the Weight of Each Index of Mixed Coal. A case study of the flammability index is considered, 
and the information entropy of flammability index is given by

$$
\begin{aligned}
e_{1} & =-k \sum_{i=1}^{m} v_{i 1} \ln v_{i 1}, \\
k & =\frac{1}{(\ln m)}=\frac{1}{(\ln 10)}=0.4343 .
\end{aligned}
$$

Based on the data and the above analysis, we can acquire the following formula:

$$
\begin{aligned}
e_{1}= & -0.4343 \sum_{i=1}^{10} y_{i 1} \ln y_{i 1} \\
= & -0.4343 \times(0.1018 \times \ln 0.1018+0.0874 \times \ln 0.0874 \\
& +\cdots+0.0917 \times \ln 0.0917)=0.99199 .
\end{aligned}
$$

In order to calculate the evaluation information entropy index, we have

$$
\begin{aligned}
& e_{1}=0.99199, \\
& e_{2}=0.98114, \\
& e_{3}=0.99993, \\
& e_{4}=0.99256 .
\end{aligned}
$$

The degree of dispersion of $j$ index is $p_{j}=1-e_{j}$. The $p_{j}$ of each evaluation index can be obtained

$$
\begin{aligned}
& p_{1}=0.00801, \\
& p_{2}=0.01886, \\
& p_{3}=0.00007, \\
& p_{4}=0.00744 .
\end{aligned}
$$

And then, we can use Formula (4) of weight as

$$
\begin{aligned}
Q_{j} & =\frac{p_{j}}{\sum_{i=1}^{m} p_{j}}, \\
Q_{1} & =\frac{0.00801}{(0.00801+0.01886+0.00007+0.00744)}=0.232916 .
\end{aligned}
$$

In order to calculate the weight of other indicators, the calculation results are as follows:

$$
\begin{aligned}
& Q_{1}=0.232916, \\
& Q_{2}=0.548634, \\
& Q_{3}=0.001943, \\
& Q_{4}=0.216507 .
\end{aligned}
$$

5.3. Matrix of Weighted Standard Decision of Each Scheme.

$$
\begin{aligned}
R & =\left[\begin{array}{ccc}
q_{1} y_{11} & \cdots & q_{n} y_{1 n} \\
\vdots & \ddots & \vdots \\
q_{1} y_{m 1} & \cdots & q_{n} y_{m n}
\end{array}\right]=\left[\begin{array}{ccc}
r_{11} & \cdots & r_{1 n} \\
\vdots & \ddots & \vdots \\
r_{m 1} & \cdots & r_{m n}
\end{array}\right] \\
& =\left[\begin{array}{cccc}
0.023700 & 0.055473 & 0.000194 & 0.021634 \\
0.020365 & 0.039362 & 0.000196 & 0.027678 \\
0.018558 & 0.034288 & 0.000199 & 0.021464 \\
0.021601 & 0.061345 & 0.000198 & 0.027847 \\
0.025215 & 0.053260 & 0.000190 & 0.015420 \\
0.018985 & 0.041294 & 0.000194 & 0.022820 \\
0.020355 & 0.050406 & 0.000189 & 0.021860 \\
0.028854 & 0.075619 & 0.000191 & 0.015646 \\
0.033935 & 0.091669 & 0.000192 & 0.022933 \\
0.021348 & 0.045919 & 0.000200 & 0.019205
\end{array}\right] .
\end{aligned}
$$

5.4. Index of the Most Ideal and the Worst (Least) Case. By using the above matrix, it can be obtained that the most ideal index weighted value set $R^{+}$and the most nonideal index weighted value set $R^{-}$

$$
\begin{aligned}
& R^{+}=\left\{R_{1}^{+}=r_{91}, R_{2}^{+}=r_{92}, R_{3}^{+}=r_{103}, R_{4}^{+}=r_{44}\right\} \\
& R^{-}=\left\{R_{1}^{-}=r_{31}, R_{2}^{-}=r_{32}, R_{3}^{-}=r_{73}, R_{4}^{-}=r_{54}\right\}
\end{aligned}
$$

5.5. Calculation of the Distance. The distance of each program and positive ideal can be obtained by Formula (10):

$$
\begin{aligned}
& L_{1}^{+}=0.034998, \\
& L_{2}^{+}=0.050763, \\
& L_{3}^{+}=0.056539, \\
& L_{4}^{+}=0.029694, \\
& L_{5}^{+}=0.038270, \\
& L_{6}^{+}=0.049611, \\
& L_{7}^{+}=0.040759, \\
& L_{8}^{+}=0.018578, \\
& L_{9}^{+}=0.006354, \\
& L_{10}^{+}=0.045101,
\end{aligned}
$$

In a similar manner, the distance between each program and negative ideal can be acquired as 


$$
\begin{aligned}
& L_{1}^{-}=0.022798, \\
& L_{2}^{-}=0.013280, \\
& L_{3}^{-}=0.005864, \\
& L_{4}^{-}=0.030052, \\
& L_{5}^{-}=0.020267, \\
& L_{6}^{-}=0.010229, \\
& L_{7}^{-}=0.017588, \\
& L_{8}^{-}=0.042780, \\
& L_{9}^{-}=0.060033, \\
& L_{10}^{-}=0.012672 .
\end{aligned}
$$

5.6. The Determination of Comprehensive Evaluation Index and Relative Approach Degree. The close degree between each scheme and the optimal plan are calculated according to the formula of $S_{i}=L_{i}^{-} /\left(L_{i}^{+}+L_{i}^{-}\right)$:

$$
\begin{aligned}
& S_{1}=0.394454, \\
& S_{2}=0.207358, \\
& S_{3}=0.093975, \\
& S_{4}=0.502989, \\
& S_{5}=0.346227, \\
& S_{6}=0.170941, \\
& S_{7}=0.301438, \\
& S_{8}=0.697222, \\
& S_{9}=0.904285, \\
& S_{10}=0.219341 .
\end{aligned}
$$

The relative closeness of the size of the order is $\mathrm{S} 9>\mathrm{S} 8>\mathrm{S} 4>\mathrm{S} 1>\mathrm{S} 5>\mathrm{S} 7>\mathrm{S} 10>\mathrm{S} 2>\mathrm{S} 6>\mathrm{S} 3$, so that the 10 kinds of mixed coal blending schemes are sorted by superior to inferior as program $9>$ program $8>$ program $4>$ program $1>\operatorname{program} 5>\operatorname{program} 7>\operatorname{program} 10>\operatorname{program} 2>$ program $6>$ program 3 .

This analysis results indicate that the lignite of Xiaolongtan, lignite of Zhaotong, and bituminous coal of Fuyuan can be mixed based on the ratio $2: 1: 2$, which is the optimal ratio of these proportions.

\section{Conclusion}

The combustion of single coal and mixed coal of Xiaolongtan lignite, Fuyuan bituminous coal, and Zhaotong lignite are studied, and the combustion characteristics are compared. The thermogravimetric experiments were carried out on coal samples. The flammability index, comprehensive combustion characteristic index, burnout temperature, and economic costs are used in TOPSIS method to measure the advantages and disadvantages of the mixing scheme with different parameters of mixed coals. Calculations are carried out and validate the proposed mix schemes of 10 groups. The advantage and disadvantage of 10 groups of mixed coal blending schemes are obtained. The best matching effect is program 9 while the worst matching effect is program 3 .
When the lignite of Xiaolongtan, lignite of Zhaotong, and bituminous coal of Fuyuan are mixed with proportion $2: 1: 2$, the mixed coal would have the best characteristics, when the lignite of Xiaolongtan, lignite of Zhaotong, and bituminous coal of Fuyuan are mixed based on the proportion $0: 2: 1$, the characteristics of mixed coal would be the worst.

\section{Data Availability}

For data availability, if the researcher needs data of this article, the corresponding author can provide the experiment data.

\section{Conflicts of Interest}

The authors of this work declare that there are no conflicts of interest regarding the publication of this paper.

\section{Acknowledgments}

This work was supported by National Natural Science Foundation of China under Contract (no. 51566005, 51064015).

\section{References}

[1] J. C. Sui, Y.-G. Du, Y. Liu, and M.-H. Xu, "Status quo of the study on the development of coal combustion in China and its development trend," Journal of Engineering for Thermal Energy and Power, vol. 101, pp. 156-160, 2008.

[2] T. Yang, Y. P. Zhang, X. U. Xing, and S. H. Huang, "Study on combustion characteristics of blended coals in a 600MW boiler unit," Power Equipment, vol. 4, pp. 233-236, 2010.

[3] B. Goshayeshi and J. C. Sutherland, "A comparison of various models in predicting ignition delay in single-particle coal combustion," Combustion and Flame, vol. 161, no. 7, pp. 1900-1910, 2014.

[4] X. Zhang, Y. Liu, C. Wang, and D. Che, "Experimental study on interaction and kinetic characteristics during combustion of blended coals," Journal of Thermal Analysis and Calorimetry, vol. 107, no. 3, pp. 935-942, 2012.

[5] G. C. Sun, X. Z. Yan, and D. L. Chen, "The application of TOPSIS method for optimizing coal blending," Clean Coal Technology, vol. 3, 2008.

[6] Y. H. Li, H. W. Chen, J. Z. Liu, Z. X. Feng, J. W. Zhang, and Q. L. Huang, "Numerical simulation of blending coals combustion of $800 \mathrm{MW}$ boiler," Proceedings of the CSEE, vol. 6, 2002.

[7] E. Rokni, A. Panahi, X. Ren, and Y. A. Levendis, "Reduction of sulfur dioxide emissions by burning coal blends," Journal of Energy Resources Technology, vol. 138, no. 3, article 032204, 2016.

[8] E. K. Boukas and R. P. Malhamé, Eds., Analysis, Control and Optimization of Complex Dynamic Systems, Springer, 2005.

[9] F. Rubiera, A. Arenillas, B. Arias, and J. J. Pis, "Modification of combustion behaviour and NO emissions by coal blending," Fuel Processing Technology, vol. 77-78, pp. 111-117, 2002.

[10] C. Wang, Y. Liu, X. Zhang, and D. Che, "A study on coal properties and combustion characteristics of blended coals in Northwestern China," Energy \& Fuels, vol. 25, no. 8, pp. 3634-3645, 2011. 
[11] H. Peng, Y. C. Yuan, and B. Wang, "Application of the GA-BP network for predicting the blended coals quality and combustion characteristics," Energy Research and Information, vol. 4, 2011.

[12] Q. Guo, Z. Zhou, F. Wang, and G. Yu, "Slag properties of blending coal in an industrial OMB coal water slurry entrained-flow gasifier," Energy Conversion and Management, vol. 86, pp. 683-688, 2014.

[13] O. Khalaf, "Thermal analysis on combustion characteristics of several soft coals and blended coals," Northeastern Electric Power Technology, vol. 4, 2004.

[14] D. Peralta, N. P. Paterson, D. R. Dugwell, and R. Kandiyoti, "Coal blend performance during pulverised-fuel combustion: estimation of relative reactivities by a bomb-calorimeter test," Fuel, vol. 80, no. 11, pp. 1623-1634, 2001.

[15] B. Arias, C. Pevida, F. Rubiera, and J. J. Pis, "Effect of biomass blending on coal ignition and burnout during oxy-fuel combustion," Fuel, vol. 87, no. 12, pp. 2753-2759, 2008.

[16] C. Moon, Y. Sung, S. Ahn, T. Kim, G. Choi, and D. Kim, "Effect of blending ratio on combustion performance in blends of biomass and coals of different ranks," Experimental Thermal and Fluid Science, vol. 47, pp. 232-240, 2013.

[17] G. Qu, "Research status and prospect of steam coal blending optimization," Clean Coal Technology, vol. 21, pp. 6-10, 2015.

[18] B. Mareschal and J. P. Brans, "Geometrical representations for MCDA," European Journal of Operational Research, vol. 34, no. 1, pp. 69-77, 1988.

[19] H. S. Shih, H. J. Shyur, and E. S. Lee, "An extension of TOPSIS for group decision making," Mathematical and Computer Modelling, vol. 45, no. 7-8, pp. 801-813, 2007.

[20] M. Behzadian, S. Khanmohammadi Otaghsara, M. Yazdani, and J. Ignatius, "A state-of the-art survey of TOPSIS applications," Expert Systems with Applications, vol. 39, no. 17, pp. 13051-13069, 2012.

[21] V. Capasso and J. Périaux, Eds., Multidisciplinary Methods for Analysis Optimization and Control of Complex Systems, Mathematics in Industry, Springer, 2005.

[22] S. Nakayama, Y. Noguchi, T. Kiga et al., "Pulverized coal combustion in $\mathrm{O}_{2} / \mathrm{CO}_{2}$ mixtures on a power plant for $\mathrm{CO}_{2}$ recovery," Energy Conversion and Management, vol. 33, no. 5-8, pp. 379-386, 1992.

[23] P. A. Bejarano and Y. A. Levendis, "Single-coal-particle combustion in $\mathrm{O}_{2} / \mathrm{N}_{2}$ and $\mathrm{O}_{2} / \mathrm{CO}_{2}$ environments," Combustion and Flame, vol. 153, no. 1-2, pp. 270-287, 2008.

[24] M. R. Akbarzadeh-Totonchi, Fuzzy Control and Evolutionary Optimization of Complex Systems, [Ph.D. Thesis], The University of New Mexico, 1998.

[25] D. Chmúrny and R. Chmúrny, "Optimization and control of complex systems: new decomposition coordination methods using back information from real complex," Systems Analysis Modelling Simulation, vol. 22, pp. 185-223, 1996.

[26] D. Tomić and B. Pernarić, "Control and optimization of complex biological systems," in 2014 37th International Convention on Information and Communication Technology, Electronics and Microelectronics (MIPRO), pp. 222-227, Opatija, Croatia, 2014.

[27] W. Zheng, "Optimization of BF pulverized coal blending based on TOPSIS method," Energy for Metallurgical Industry, vol. 1, 2013. 


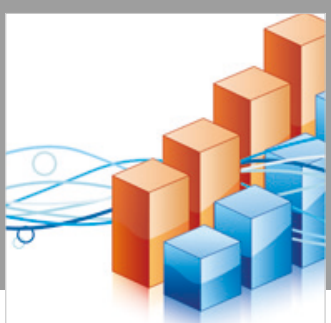

Advances in

Operations Research

\section{-n-m}
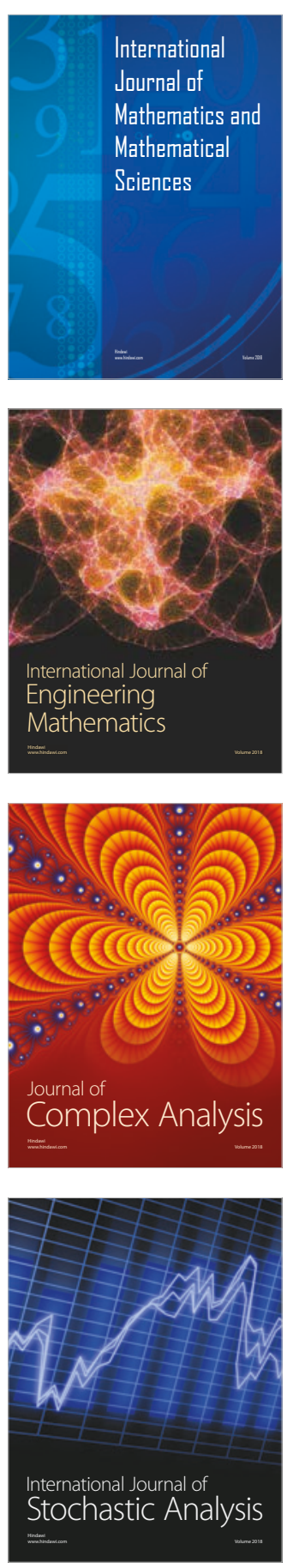
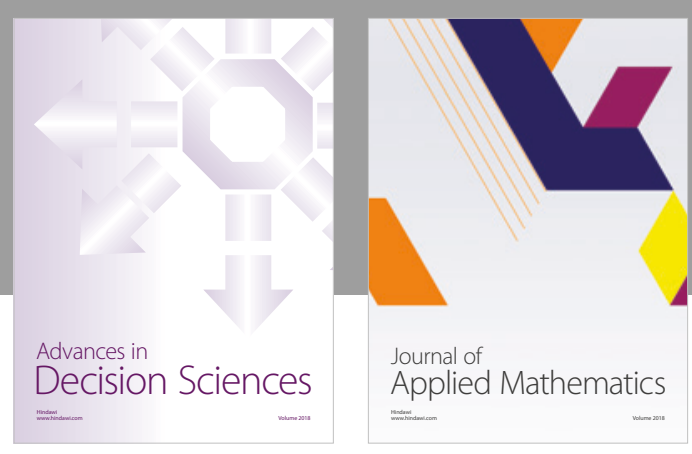

Journal of

Applied Mathematics
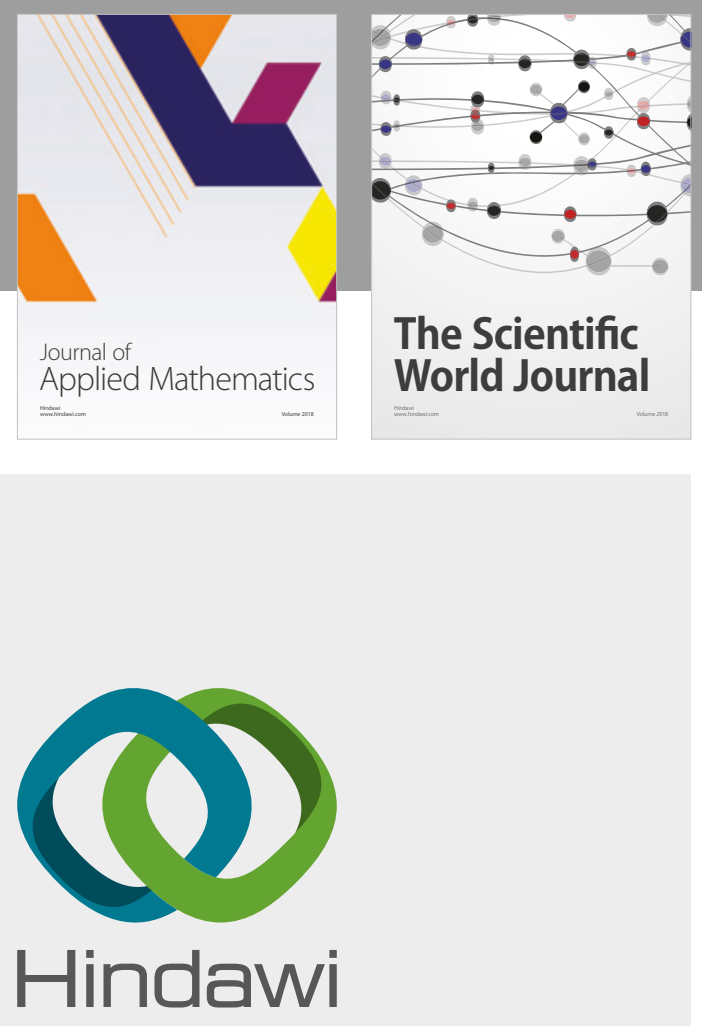

Submit your manuscripts at

www.hindawi.com

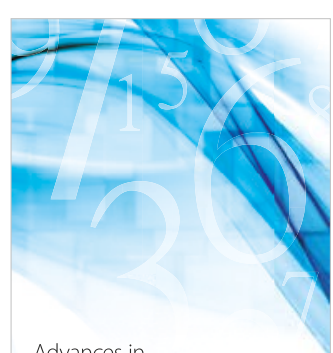

Advances in
Numerical Analysis
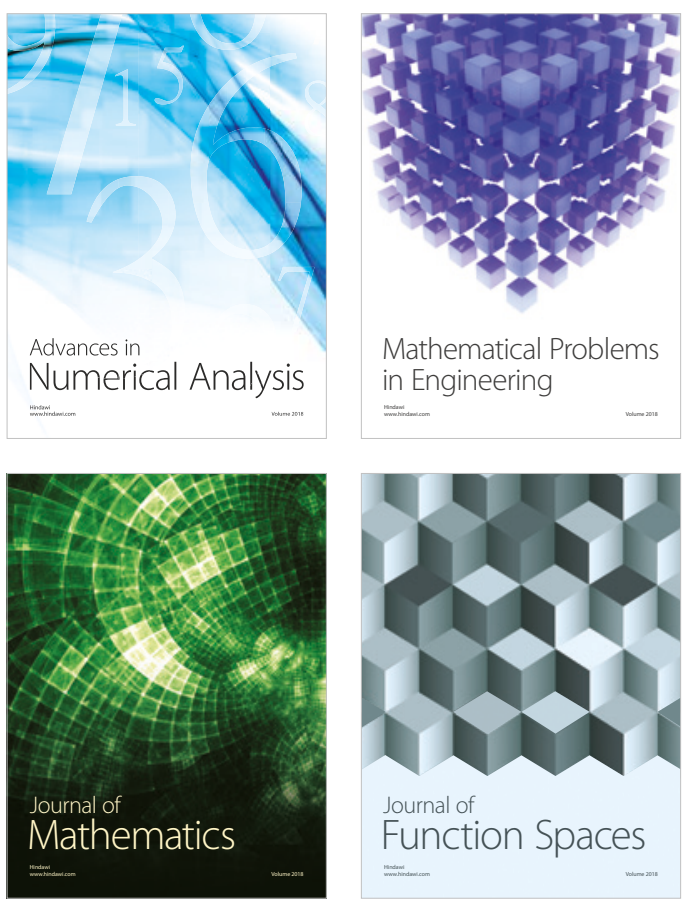

Mathematical Problems in Engineering

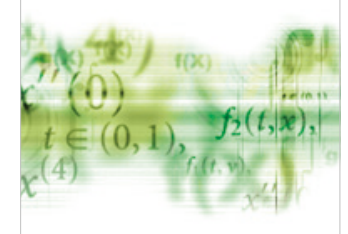

International Journal of

Differential Equations

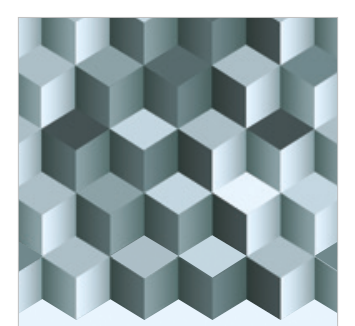

Journal of

Function Spaces
The Scientific

World Journal

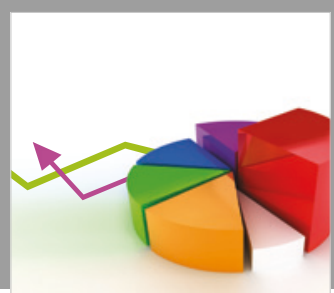

Journal of

Probability and Statistics
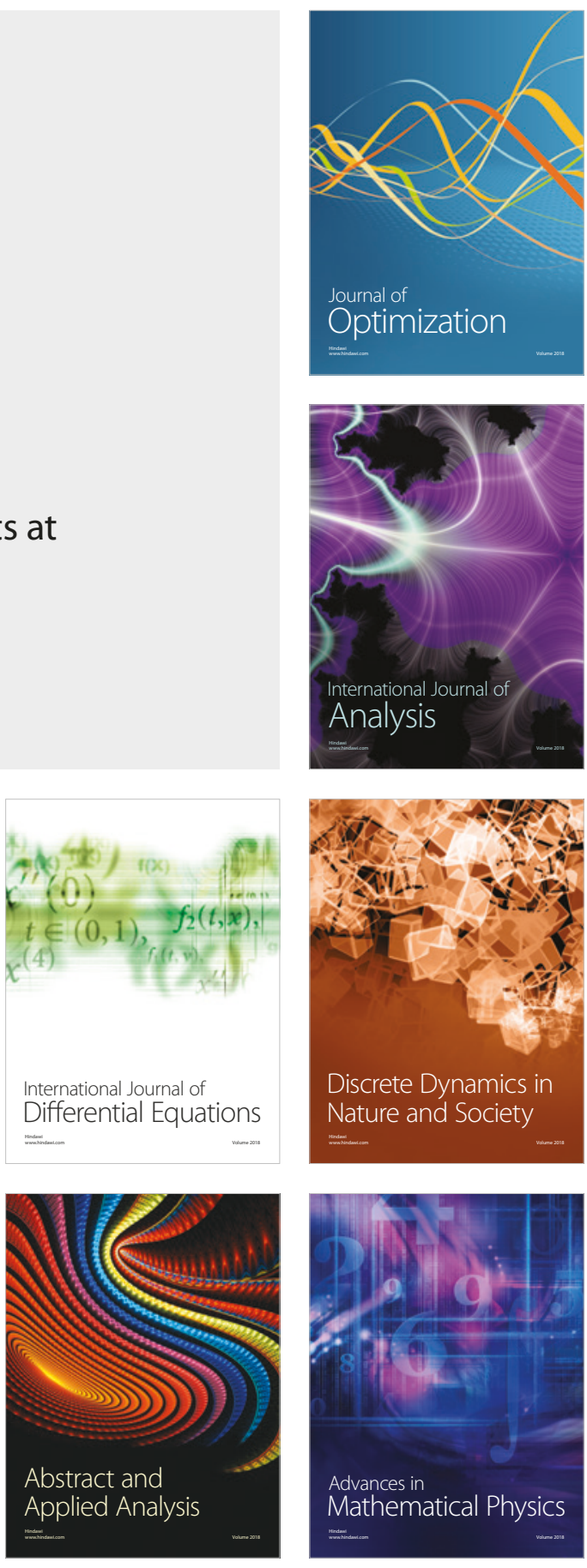